\title{
Polypharmacy in the oldest old ( $\geq 80$ years of age) patients in China: a cross-sectional study
}

\author{
Xiaoxing Lai ${ }^{1 *} \mathbb{D}$, Hongwei Zhu', Xiaopeng Huo ${ }^{1}$ and Zheng $\mathrm{Li}^{\mathrm{i}^{*}}$
}

\begin{abstract}
Background: The oldest old generally have worse health and more comorbidities than the general population of older adults, and they are more likely to be exposed to polypharmacy. Reliable investigation of polypharmacy among the oldest old ( $\geq 80$ years of age) in China are lacking. So this study aims to describe the polypharmacy status of oldest old patients $\geq 80$ years of age and to assess the factors influencing medication compliance.

Methods: This was a cross-sectional study of 258 oldest old patients $\geq 80$ years of age and hospitalized at a tertiary hospital in Beijing between December 1, 2014 and June 30, 2015. They completed three validated questionnaires to assess their pre-admission status (general demographics, medication knowledge, and medication adherence). Potentially inappropriate medications (PIM) use was evaluated by physicians.

Results: The majority of the patients (55.4\%) took $<10$ types of drugs. The numbers of drugs taken ranged from 8 to 60 drugs (median of 22.9). Patients taking 11-20 drugs accounted for $46.1 \%$ of the patients. Subjects with a history of adverse drug reactions accounted for $40.3 \%$. The proportion of PIMs was $27.1 \%$. Compliance was only 32. $6 \%$ among the oldest old patients with polypharmacy. Age and medication classes were independently negatively associated with compliance, and medication knowledge was independently positively associated with compliance.
\end{abstract}

Conclusion: Oldest old patients ( $\geq 80$ years of age) had a poor medication knowledge. Age, medication classes, and medication knowledge were independently associated with medication compliance.

Keywords: Oldest old, Polypharmacy, Non-adherence, Medication knowledge

\section{Background}

The China Report of the Development on Aging Cause Blue Book [1] reported that the number of old individuals in China exceeded 200 million in 2013, and that up to 22.73 million of these individuals were $\geq 80$ years old. The Aging Committee of China predicts that the number of oldest old $\geq 80$ years old in China will reach 30.67 million by 2020 , accounting for $12.37 \%$ of the old population.

Harboring multiple comorbidities is a common fact among the older adults, who often have to be treated with a combination of drugs, leading to polypharmacy. Currently, there is no universally accepted definition of polypharmacy, although it is generally considered as

\footnotetext{
*Correspondence: laixx86@163.com; lizheng6080@163.com 'Department of Health Care, Peking Union Medical College Hospital, Beijing 100730, China

${ }^{2}$ School of Nursing, Peking Union Medical College, Beijing 100730, China
}

being the use of $\geq 5$ types of medications [1-3]. In the nursing home setting, an American study showed that $34.8 \%$ of the patients $>85$ years of age were taking at least nine drugs [4]. A Canadian study showed that $15.5 \%$ of the nursing home residents were on at least nine medications [5]. In China, a study showed that among patients of 80-104 years of age, the medication exposure rate was $100 \%$, with $70 \%$ of them taking at least 6 drugs [6].

Despite the fact that drugs are prescribed to deal with specific diseases and comorbidities, polypharmacy is associated with consequences detrimental to the patient and with a burden to the society. A study showed that polypharmacy was associated with an increase of $30 \%$ in medical costs [7]. In addition, taking multiple drugs increases the risk of adverse reactions and drug interactions. In 2005, it has been estimated that 4.3 million 
medical consultations were directly associated with drug adverse reactions [8], with $10 \%$ of all emergency admission being due to an adverse reaction [9]. About $40 \%$ of hospitalized older adults will experience an adverse drug reaction [8]. A study showed that older adults taking 59 drugs had a $50 \%$ probability of drug interaction, increasing to $100 \%$ for those taking $\geq 20$ drugs [10]. Among older adults, polypharmacy has been associated with declining functional status, cognitive impairment, falls, urinary incontinence, and impaired nutritional status [11-13]. These adverse outcomes of polypharmacy have also been observed in Chinese oldest old $\geq 80$ years of age [6].

Non-adherence is one of the most important negative impacts of polypharmacy, with rates of $43-100 \%$ among different communities of oldest old patients [14, 15]. Non-adherence may have dire impacts on the patients' life [14, 16, 17]. Ulfvarson et al. [18] claimed that only $30 \%$ of Swedish older adults who had been discharged for one week fully adhered to medical instructions regarding their prescribed drugs. Therapeutic failure leading to hospitalization, additional drugs, additional medical/surgical procedures, and increased health costs (both to the patient and society) are important consequences of treatment non-adherence [14, 16, 17].

Reliable knowledge of polypharmacy among the oldest old ( $\geq 80$ years of age) in China is lacking. The oldest old generally have worse health and more comorbidities than the general population of older adults, and they are more likely to be exposed to polypharmacy $[4,5,19]$. In addition, a better understanding of what influences older adults' level of medication compliance may help health care providers to find appropriate ways to improve medication compliance. This question is particularly important because of the aging population in China and in the world in general. Therefore, the aims of the present study were to describe the polypharmacy status of the oldest old patients ( $\geq 80$ years of age) and to assess the factors influencing medication compliance in patients with polypharmacy in Beijing.

\section{Methods}

\section{Study design and subjects}

This was a cross-sectional study (convenience sample) of 258 oldest old patients ( $\geq 80$ years of age) and hospitalized at a tertiary hospital in Beijing between December 1, 2014 and June 30, 2015. Their pre-admission status was assessed using three validated questionnaires. The study was approved by the ethics committee of the hospital. All patients provided a written informed consent.

The inclusion criteria were: 1 ) $\geq 80$ years of age; 2 ) at least one chronic disease, selected basing on "China Report of the Development on Aging Cause Blue Book" [1] and "Report of Status and Trend in Development of
Chronic Diseases in Older Adults in China", which was published by China Research Center on Aging (hypertension, coronary heart disease, diabetes mellitus, hyperlipidemia, chronic gastritis, chronic low back pain, atherosclerosis, respiratory disease, or skin or tissue disease); and 3) taking $\geq 5$ types of medications before admission (including prescription medications but not including non-prescription medications or over-thecounter health care products). The exclusion criteria were: 1) life-threatening or terminal disease; 2) mental disorder or cognitive impairment; 3) or unwilling to participate.

\section{Questionnaires and data collection}

Following an explanation of the purpose of the study, consent was obtained from patients who met the eligibility criteria and agreed to participate. Demographic and medical data were obtained from the patients and their medical records. The three questionnaires took approximately $20 \mathrm{~min}$ to fill and the patients filled the questionnaires at the hospital. Pill boxes were provided as an incentive for participation. Before the patients completed the questionnaires, the meaning and requirement of all items were explained in details by a healthcare professional. The questionnaires were filled by the patients, without help, and in the presence of the professional. All questionnaires covered the pre-admission period.

The general demographic questionnaire included sex, age, educational level, marital status, and payment of medical expenses. The subjects also provided a selfevaluation of their health status, the types and number of diseases they had, and the number and names of the drugs they were taking. This information was validated using the patient's medical records. For analysis convenience, medications were recorded and coded according to "Practical Drug Code for Hospital Pharmacy" which is occupation standard of medicine in China and used in hundreds of medical organizations, compiled and published by Pharmacy Department of Peking Union Medical College Hospital.. History of adverse reactions (ADR) was obtained from the patients' medical records and the ADR Monitoring System of the hospital. ADR monitoring system was based on Hospital Information System (HIS) System of internal network in Peking Union Medical College Hospital. Electronic system simplified the procedure of reporting and recorded all the ADRs roundly. The reporter could inquire about the content of the report and consult the feedback content in time by the system.

The medication knowledge questionnaire was developed by the authors based on an extensive literature review of Chinese and English papers [20-27], relevant work experience, and suggestions from five geriatrists and pharmacists. The resulting questionnaire was revised by a group 
of faculty members from a hospital in Beijing. The content validity was evaluated by five geriatrists and pharmacists. A strong positive correlation was defined as 4 points, positive correlation as 3 points, weak correlation as 2 points, and no correlation as 1 points. The content validity index (CVI) of the questionnaire was 0.96 , and the CVI of the items ranged from $0.71-1.00$. The Cronbach's $\alpha$ was calculated as a measure of the internal validity of the questionnaire and was 0.82. The questionnaire (English translation, non-validated) is presented as Additional file 1. The questionnaire was also assessed for ease of comprehension and readability by 15 oldest old patients with polypharmacy (not participating in the present study).

This questionnaire included eight dimensions and 25 questions. The content of the items addressed the subjects' knowledge about: 1) medication delivery modes; 2) medication dosage; 3) the importance of taking medications regularly; 4) drug side effects; 5) the dangers of drug abuse (self-medication without a doctor's guidance and/or beyond the medical scope of treatment and dose standards); 6) how to identify expired drugs; 7) drug incompatibilities; and 8) drug storage. The average awareness level was calculated as the number of questions answered correctly divided by the total number of questions.

The 4-item Morisky scale was used to assess medication compliance [28]. Xu et al. [29] evaluated the internal reliability of the Chinese version of the Morisky scale in Chinese patients and reported a Cronbach's $\alpha$ of 0.715 . The scale consists of four questions regarding the 6 months prior to admission: 1) Have you ever forgotten to take your medicine? 2) Are you careless about taking your medicine? 3) Do you sometimes stop taking your medicine when you feel better? 4) Sometimes, if you feel worse when you take your medicine, do you stop taking it? The patients were considered adherent if their answers to all four questions were "No", and they were considered poorly adherent if one or more of their responses was "Yes". The rate of medication adherence was defined as the number of compliant subjects divided by the total number of subjects.

\section{Potentially inappropriate medications (PIMs)}

The 2012 American Geriatrics Society's updated Beers criteria [30] were used to assess PIMs. The new 2012 Beers criteria were translated into Chinese and adapted in accordance with the National Essential Drugs List of China (2009 edition), omitting medicines unapproved in China [31]. PIMs were defined as drugs with a potential for harm that outweighed their benefits. The medication review chart was used to assess PIMs comprehensively, and the medication review chart (English translation, non-validated) is presented as Additional file 2. In this study, PIM was evaluated by five attending physicians (all had medical doctor degree, and worked in geriatric wards as attending physicians at least 5 years). At least one inappropriate medication in the patient's prescription regimen, as based on the 2012 Beers criteria, was considered to indicate the use of PIMs.

\section{Data analysis}

Data were analyzed with descriptive and inferential statistics using SPSS 17.0 (IBM, Armonk, NY, USA). Descriptive statistics were reported as mean, standard deviation, proportion, and percentage. Inferential procedures were also used including univariate and multivariate logistic regression. Two-sided $P$-values $<0.05$ were considered statistically significant.

\section{Results}

\section{Characteristics of the subjects}

Of the 258 subjects, the age range was from 80 109; mean age was $88.7 \pm 6.5$ years. Among the subjects, males represented $58.9 \%$. The majority $(55.8 \%)$ of the patients lived with their spouses and $96.9 \%$ of the subjects received free medical care or were covered by health insurance. The majority of patients (53.9\%) had junior college diplomas, and $24.7 \%$ had middle-school education or below (Table 1).

\section{Chronic diseases}

The number of chronic diseases was 3-13/subject (mean of $7.0 \pm 2.3$ ). The five most common chronic

Table 1 Baseline characteristics of oldest old patients $>80$ years of age with polypharmacy $(n=258)$

\begin{tabular}{|c|c|c|c|c|}
\hline Index & Stratification & Mean \pm SD & $n$ & $\%$ \\
\hline Age (years) & & $88.7 \pm 6.5$ & & \\
\hline \multirow[t]{2}{*}{ Gender } & Male & & 152 & 58.9 \\
\hline & Female & & 106 & 41.1 \\
\hline \multirow[t]{2}{*}{ Marital status } & Have spouse & & 161 & 62.4 \\
\hline & No spouse & & 97 & 37.6 \\
\hline \multirow[t]{4}{*}{ Living status } & Living alone & & 16 & 6.2 \\
\hline & Living with spouse & & 144 & 55.8 \\
\hline & $\begin{array}{l}\text { Living with } \\
\text { housekeeper }\end{array}$ & & 42 & 16.3 \\
\hline & Living with offspring & & 56 & 21.7 \\
\hline \multirow[t]{3}{*}{ Medical expenses } & Self-paid & & 8 & 3.1 \\
\hline & Health insurance & & 99 & 38.4 \\
\hline & Publicly paid & & 151 & 58.5 \\
\hline \multirow[t]{3}{*}{ Health condition } & Good & & 29 & 11.2 \\
\hline & Moderate & & 111 & 43.0 \\
\hline & Poor & & 118 & 45.7 \\
\hline $\begin{array}{l}\text { Number of diagnosed } \\
\text { diseases }\end{array}$ & & $7.0 \pm 2.3$ & & \\
\hline
\end{tabular}


diseases were hypertension $(n=160,62.0 \%)$, hyperlipidemia $(n=112,43.4 \%)$, atherosclerosis $(n=111$, $43.0 \%)$, chronic gastritis $(n=106,41.4 \%)$, and coronary heart disease $(n=105,40.7 \%)$ (Table 2).

\section{Medications}

The five most commonly used prescription drugs were: gastrointestinal drugs $(n=199)$, vitamins and minerals $(n=185)$, traditional Chinese medications (TCM, refer particularly to Chinese patent medicines, which were produced by traditional Chinese herbal medicine according to the formulary prescription and preparation process, and had definite and systemic effects.) $(n=156)$, osteoporosis prevention drugs $(n=143)$, and antithrombotic drugs $(n=142)$ (Table 3$)$.

The maximum number of types of medications used by the oldest old with polypharmacy was 27 . The majority of the subjects $(55.4 \%)$ took $<10$ types of drugs. Patients taking 11-20 pills/tablets of drugs accounted for $46.1 \%$ of the patients. Subjects with a history of adverse drug reactions accounted for $40.3 \%$. In addition, $60.5 \%$ of the subjects took Chinese traditional medicines, and $64.7 \%$ of the subjects used over-the-counter health care products (Table 4 ).

\section{Medication knowledge}

The average accuracy of the subjects' responses to the medication knowledge items was $68.7 \%$. The items with the highest average numbers of correct responses included those on expired drugs, medication types, and drug storage, whereas the items with the lowest awareness were about drug side effects, drug abuse, drug incompatibility, and medication dosage (Table 5). Correlations were identified between age and medication knowledge; medication types and medication knowledge; and numbers of drugs and medication knowledge. Medication knowledge declined with increasing age: for each one-unit increase in age, the average medication knowledge score decreased by $0.697(r=-0.697, P<0.05)$.

Table 2 Distribution of chronic diseases

\begin{tabular}{llll}
\hline Rank & Chronic disease & $n$ & $\%$ \\
\hline 1 & Hypertension & 160 & 62.0 \\
2 & Hyperlipidemia & 112 & 43.4 \\
3 & Atherosclerosis & 111 & 43.0 \\
4 & Chronic gastritis & 106 & 41.1 \\
5 & Coronary heart disease & 105 & 40.7 \\
6 & Diabetes mellitus & 98 & 38.0 \\
7 & Skin and tissue disease & 87 & 33.7 \\
8 & Chronic low back pain & 75 & 29.1 \\
9 & Respiratory diseases & 69 & 26.7 \\
\hline
\end{tabular}

Table 3 Distribution of drugs regularly taken by the patients

\begin{tabular}{llll}
\hline Rank & Drug & $n$ & $\%$ \\
\hline 1 & Gastrointestinal drugs & 199 & 77.1 \\
2 & Vitamins and minerals & 185 & 71.7 \\
3 & Traditional Chinese medicine & 156 & 60.5 \\
4 & Osteoporosis preventing drugs & 143 & 55.4 \\
5 & Antithrombotic drugs & 142 & 55.0 \\
6 & B-blockers & 120 & 46.5 \\
8 & Anti-constipation drugs & 102 & 39.5 \\
9 & Prostate treatment drugs & 98 & 38.0 \\
10 & Statins & 69 & 26.7 \\
\hline
\end{tabular}

\section{PIM}

The proportion of PIMs prescribed to oldest old patients with polypharmacy was $27.1 \%$. Based on the prescriptions of the 258 subjects, there were a total of 70 PIMs prescribed for 61 patients. The specific distribution is shown in Table 6.

\section{Compliance}

In this study, only $32.6 \%$ of the oldest old patients with polypharmacy were compliant to their treatment regimen. Of the four items on the Morisky scale, compliance was the lowest $(50.0 \%)$ for forgetting to take medicines and the highest $(59.3 \%)$ for sometimes being careless about taking medicine.

\section{Factors influencing compliance}

Ten variables (gender, age, education level, marital status, medical costs, disease diagnosis, medication classes,

Table 4 Number of drug types, drug numbers, frequencies of adverse drug reactions, and use of Chinese traditional medicines and health care products

\begin{tabular}{llll}
\hline Index & Stratification & $n$ & $\%$ \\
\hline Drug types & $<10$ & 143 & 55.4 \\
& $10-15$ & 59 & 22.9 \\
& $>15$ & 56 & 21.7 \\
Number of drug types & $\leq 10$ & 9 & 3.5 \\
& $11-20$ & 119 & 46.1 \\
& $21-30$ & 81 & 31.4 \\
Adverse drug reactions & $>30$ & 49 & 19.0 \\
& Yes & 104 & 40.3 \\
& No & 95 & 36.8 \\
Use of Chinese traditional medicines & Uncertain & 59 & 22.9 \\
& Yes & 156 & 60.5 \\
Use of over-the-counter health care products & Yes & 102 & 39.5 \\
& No & 91 & 35.3 \\
\hline
\end{tabular}


Table 5 Medication knowledge among oldest old patients > 80 years of age with polypharmacy

\begin{tabular}{lll}
\hline Dimension (points) & Score & $\begin{array}{l}\text { Average awareness } \\
\text { rate (\%) }\end{array}$ \\
\hline Total score (100) & $68.7 \pm 12.2$ & 68.7 \\
Medication mode (8) & $5.7 \pm 2.2$ & 71.3 \\
Medication dosage (12) & $8.1 \pm 3.4$ & 67.5 \\
Regular medication (12) & $8.5 \pm 2.8$ & 70.8 \\
Drug side effects (12) & $6.7 \pm 2.8$ & 55.8 \\
Drug abuse (16) & $10.1 \pm 3.5$ & 63.1 \\
Expired drugs (16) & $12.3 \pm 2.5$ & 76.9 \\
Drug incompatibility (4) & $2.7 \pm 1.9$ & 67.5 \\
Drug storage (20) & $14.7 \pm 3.5$ & 73.5 \\
\hline
\end{tabular}

quantity of drugs, adverse drug reactions, and medication knowledge) were analyzed using univariate and multivariate logistic regression analyses to determine the factors associated with compliance. The univariate logistic regression analysis showed that gender $(P<0.001)$, age $(P<0.001)$, marital status $(P=0.001)$, medical expenses $(P=0.003)$, disease diagnosis $(P<0.001)$, medication classes $(P=0.001)$, number of drugs $(P=0.002)$, and medication knowledge $(P<0.001)$ were associated with compliance. These variables were entered in the multivariate logistic regression analysis, revealing that age and medication classes were independently negatively associated with compliance, and that medication knowledge was independently positively associated with compliance (Table 7).

\section{Discussion}

\section{Characteristics of the subjects}

In the present study, oldest old of $\geq 80$ years of age were specifically selected because they represent a relatively novel and expanding population in China's aging society [32]. The majority of the patients in our study lived with their spouses, which is consistent with Chinese national data and the social characteristics of oldest old living arrangements [32]. This suggests that most of the subjects did not lack for care and had some form of physical and psychological support. Regarding health care costs, $96.8 \%$ of the subjects received free medical care or had health insurance, suggesting that the patients' economic burden was light and that few of them were concerned about their medical expenses. The average number of chronic diseases per patient observed in this study was generally consistent with previous studies in China $[33,34]$. The most commonly used prescription drugs were gastrointestinal drugs. Classification statistics was conducted in the cardiovascular drugs as follow: calcium antagonists, beta blockers, thiazide drugs, angiotensin, antithrombotic drugs and statins. So the cardiovascular drugs were very commonly used in older adults if aggregated in this study..

\section{Medication knowledge and compliance}

Previous studies showed that appropriate medication knowledge was present in $60-72 \%$ of people [35-37]. In the present study, the subjects specifically lacked knowledge about drug side effects, drug abuse, and medication dosage, as supported by previous studies worldwide $[38,39]$. These findings may be related to the

Table 6 Distribution of PIMs

\begin{tabular}{|c|c|c|c|}
\hline PIM & Drug & $n$ & $\%$ \\
\hline & Central nervous system drugs: estazolam, alprazolam & 10 & 14.3 \\
\hline \multirow[t]{9}{*}{ Drugs that should be avoided by elderly people } & Gastrointestinal drugs: metoclopramide & 6 & 8.6 \\
\hline & Anticholinergic drugs: diphenhydramine, chlorpheniramine & 3 & 4.3 \\
\hline & Spironolactone $>25 \mathrm{mg} / \mathrm{d}$ & 5 & 7.1 \\
\hline & Digoxin $>0.125 \mathrm{mg} / \mathrm{d}$ & 4 & 5.7 \\
\hline & Amiodarone, propafenone & 3 & 4.3 \\
\hline & Short-acting nifedipine & 7 & 10.0 \\
\hline & Prazosin, terazosin & 4 & 5.7 \\
\hline & Ibuprofen, indomethacin & 5 & 7.1 \\
\hline & Liquid paraffin & 5 & 7.1 \\
\hline \multirow[t]{4}{*}{ Elderly-specific disease state-related PIMs } & Aspirin for heart failure & 3 & 4.3 \\
\hline & Benzodiazepines for dementia and cognitive impairment & 2 & 2.9 \\
\hline & Metoclopramide for Parkinson's disease & 3 & 4.3 \\
\hline & Theophylline for insomnia & 2 & 2.9 \\
\hline Drugs that should be used with caution by elderly people & Aspirin for primary prevention of cardiovascular events & 8 & 11.4 \\
\hline
\end{tabular}


Table 7 Multivariate logistic regression analysis

\begin{tabular}{lll}
\hline Variable & OR $(95 \% \mathrm{Cl})$ & $P$ \\
\hline Age & $0.36(0.21-0.63)$ & $<0.001$ \\
Medication types & $0.85(0.75-0.95)$ & 0.004 \\
Medication knowledge & $1.06(1.02-1.10)$ & 0.004 \\
\hline
\end{tabular}

participants' advanced age, as the regression analysis results showed that medication knowledge declined with increasing age, which is supported by previous studies in different populations worldwide [40-42]. Previous studies showed that medication knowledge is intimately associated with compliance [35, 37, 39, 43, 44], but since multiple factors are involved in compliance, medication knowledge is thought to play a relatively minor role [45]. In this study, the rate of medication compliance among the oldest old patients with polypharmacy was lower than in previous studies [14, 15, 18, 39, 41, 46, 47]. Patients may forget to take their drugs because of poor selfmanagement, poor memory, or a limited emphasis on taking routine medication [48]. It is known that medication compliance among the older adults is affected by many factors, including patient-related factors, social support, medical expenses, and the doctor-patient relationship [14, 15, 18, 39, 41, 46-48]. Although certain social demographic characteristics (e.g. age and gender) and disease factors cannot be changed, several patientrelated factors (e.g., medication knowledge level) can be intervened on, improving compliance. This study showed that age and medication classes were independently associated medication compliance, and that medication knowledge was an independent protective factor, as supported by previous studies [48-50], and could be more important to medication compliance than previously suggested [45]; nevertheless, the present study examined Chinese patients $\geq 80$ years old, while Lam et al. [45] examined Australian patients $\geq 65$ years of age.

The use of an excessive number of types of drugs can increase the risk of adverse drug reactions and the complexity of dosing (e.g., the method of administration and frequency of medication use). The numbers of drugs used in the present study were higher than those reported in previous studies [12, 51, 52]. Traditional Chinese medicine must be considered since it is generally not used outside China, is counted when evaluating polypharmacy, and can lead to adverse drug reactions [53]. In the present study, the proportion of elderly patients taking traditional Chinese medicine was high, highlighting the potentially high impact of traditional Chinese medicine on polypharmacy in Chinese populations. In addition, the proportion of oldest old patients using over-the-counter health care products in our study was high, which was likely related to the light economic burden of the subjects. The numbers of drugs may influence patients' compliance to treatment. Indeed, patients may worry that excessive drug use could lead to adverse reactions, which may affect compliance, as supported by the fact that $40.3 \%$ of the subjects in our study had a history of adverse drug reactions, which was higher than that of previous studies [47, 54, 55]. Therefore, before drugs are prescribed, health care providers should inform their oldest old patients of the expected effects of treatment and possible side effects.

\section{PIM}

The frequency of PIM in this study was $27 \%$. A study from the Middle East showed a PIM frequency of 52.5\% [56]. A study from Taiwan revealed PIM frequencies varying between 24 and $73 \%$ among different hospitals [57]. In Europe, the frequency of PIM is around 20\% [58], while it ranges from 14 to $27 \%$ in the United States [59]. Therefore, the frequency of PIM reported in this study was comparable to that observed in other countries, and lower than in previous studies in China. Indeed, among elderly $\geq 65$ years of age, Li et al. reported a PIM frequency of $52 \%$ or $72 \%$, depending upon the definition used [60], while Zhang et al. [61] showed PIM rates of 45-54\% among hospitalized patients. These discrepancies could be due to the study population (in this study, oldest old $\geq 80$ years of age), the definition of PIM, and period covered (here, pre-admission). The benzodiazepines were commonly used of PIMs In this study. The oldest old who took the benzodiazepines were more likely to be cognitive and psychomotor impairment compared with young people. So No-drug Therapy is advised firstly for the oldest old with insomnia.

\section{Limits}

The present study is not without limitations. The sample size was relatively small and from a single center. The selection of the patients will inevitably result in biases, affecting the generalizability of the results. Finally, no control group was included and the analyses were mostly descriptive, limited the internal and external validity of the results. Additional studies are still necessary to improve drug management in elderly patients.

\section{Conclusion}

This study indicates that oldest old patients $\geq 80$ years old and with polypharmacy in China showed a low medication knowledge, low medication compliance, and high frequency of PIMs. Several factors influencing medication compliance were identified, and the findings could provide a basis for the study of rational drug use in oldest old patients with polypharmacy. 


\section{Additional files}

Additional file 1: Medication knowledge questionnaire (non-validated English version). (DOCX $17 \mathrm{~kb}$ )

Additional file 2: Medication review chart (non-validated English version) (DOC $43 \mathrm{~kb}$ )

\section{Abbreviations}

ADR: Adverse Reaction; CVI: Content Validity Index; HIS: Hospital Information System; PIM: Potentially Inappropriate Medication; TCM: Traditional Chinese Medication

\section{Acknowledgments}

None.

\section{Funding}

None.

\section{Availability of data and materials}

The datasets generated and/or analyzed during the current study are not publicly available due to the need to protect patient privacy but are available from the corresponding author on reasonable request.

\section{Authors' contributions}

LXX had full access to all data and takes responsibility for the integrity of the data and the accuracy of the data analysis. Study concept and design: LXX, ZHW, HXP, and LZ. Acquisition of data: LXX and ZHW. Analysis and interpretation of data: $L X X, H X P$, and $L Z$. Preparation of manuscript: $L X X$ and ZHW. Substantive revision of manuscript: $L X X, L Z$, and HXP. All authors read and approved the final manuscript.

\section{Ethics approval and consent to participate}

This study was approved by the Ethics Committee of Chinese Academy of Medical Sciences \& Peking Union Medical College Hospital. Following an explanation of the purpose of the study, written consent was obtained from participants.

\section{Consent for publication}

Not applicable.

\section{Competing interests}

The authors declare that they have no competing interests

\section{Publisher's Note}

Springer Nature remains neutral with regard to jurisdictional claims in published maps and institutional affiliations.

Received: 19 December 2017 Accepted: 26 February 2018

Published online: 02 March 2018

\section{References}

1. Zheng C. Guidelines for management of geriatric syndromes. Beijing: Peking Union Medical College Press; 2010

2. Fulton MM, Allen ER. Polypharmacy in the elderly: a literature review. J Am Acad Nurse Pract. 2005:17:123-32.

3. Haider SI, Johnell K, Thorslund M, Fastbom J (2008) Analysis of the association between polypharmacy and socioeconomic position among elderly aged $>$ or $=77$ years in Sweden. Clin Ther 30: 419-427.

4. Dwyer LL, Han B, Woodwell DA, Rechtsteiner EA. Polypharmacy in nursing home residents in the United States: results of the 2004 National Nursing Home Survey. Am J Geriatr Pharmacother. 2010;8:63-72.

5. Bronskill SE, Gill SS, Paterson JM, Bell CM, Anderson GM, et al. Exploring variation in rates of polypharmacy across long term care homes. Am Med Dir Assoc. 2012:13(309):e315-21.

6. Wang R, Chen L, Fan L, Gao D, Liang Z, et al. Incidence and effects of polypharmacy on clinical outcome among patients aged 80+: a five-year follow-up study. PLoS One. 2015;10:e0142123.
7. Akazawa M, Imai H, Igarashi A, Tsutani K. Potentially inappropriate medication use in elderly Japanese patients. Am J Geriatr Pharmacother. 2010;8:146-60

8. Bourgeois FT, Shannon MW, Valim C, Mandl KD. Adverse drug events in the outpatient setting: an 11-year national analysis. Pharmacoepidemiol Drug Saf. 2010;19:901-10.

9. Hohl CM, Dankoff J, Colacone A, Afilalo M. Polypharmacy, adverse drugrelated events, and potential adverse drug interactions in elderly patients presenting to an emergency department. Ann Emerg Med. 2001;38:666-71.

10. Doan J, Zakrzewski-Jakubiak H, Roy J, Turgeon J, Tannenbaum C. Prevalence and risk of potential cytochrome P450-mediated drug-drug interactions in older hospitalized patients with polypharmacy. Ann Pharmacother. 2013:47:324-32.

11. Maher RL, Hanlon J, Hajjar ER. Clinical consequences of polypharmacy in elderly. Expert Opin Drug Saf. 2014;13:57-65.

12. Field TS, Gurwitz JH, Harrold LR, Rothschild J, DeBellis KR, et al. Risk factors for adverse drug events among older adults in the ambulatory setting. J Am Geriatr Soc. 2004;52:1349-54.

13. Mansur N, Weiss A, Beloosesky Y. Is there an association between inappropriate prescription drug use and adherence in discharged elderly patients? Ann Pharmacother. 2009;43:177-84.

14. Vik SA, Maxwell CJ, Hogan DB. Measurement, correlates, and health outcomes of medication adherence among seniors. Ann Pharmacother. 2004;38:303-12.

15. Lee W, Pang KK, Hui KC, Kwok JC, Leung SL, et al. Medication adherence: is it a hidden drug-related problem in hidden elderly? Geriatr Gerontol Int. 2013;13:978-85

16. Salazar JA, Poon I, Nair M. Clinical consequences of polypharmacy in elderly: expect the unexpected, think the unthinkable. Expert Opin Drug Saf. 2007;6:695-704

17. Rollason V, Vogt N. Reduction of polypharmacy in the elderly: a systematic review of the role of the pharmacist. Drugs Aging. 2003;20:817-32.

18. Ulfvarson J, Adami J, Bardage C, von Bahr C, Wredling R. Drug use and perceived health in recently hospitalized older people. Br J Community Nurs. 2005;10:469-74.

19. Quinn KJ, Shah NH. A dataset quantifying polypharmacy in the United States. Sci Data. 2017:4:170167.

20. Zhou S, Wang J, Jiao X. Investigation and analysis on medication knowledge, belief and behavior in elderly patients with coronary heart disease. J Nurs Admin. 2006:6:1-4.

21. Shi X, Cai Y, Chen Z. Review of polypharmacy in elderly patients. Chin J Clinicians. 2011;39:29-31.

22. Liu Y, Li Y, Cheng Y. Status of knowledge and behavior of drug use among residents in 5 provinces (cities) in China in 2011. Chin J Prev Med. 2012:46:495-9

23. Jian Z. [Six medication principles for elderly people]; 2014.

24. Hsiao FY, Lee JA, Huang WF, Chen SM, Chen HY. Survey of medication knowledge and behaviors among college students in Taiwan. Am J Pharm Educ. 2006:70:30.

25. Hill J, Bird HA, Hopkins R, Lawton C, Wright V. The development and use of patient knowledge questionnaire in rheumatoid arthritis. Br J Rheumatol. 1991;30:45-9

26. Okuyan B, Sancar M, Izzettin FV. Assessment of medication knowledge and adherence among patients under oral chronic medication treatment in community pharmacy settings. Pharmacoepidemiol Drug Saf. 2013:22:209-14

27. Quinlan P, Price KO, Magid SK, Lyman S, Mandl LA, et al. The relationship among health literacy, health knowledge, and adherence to treatment in patients with rheumatoid arthritis. HSS J. 2013;9:42-9.

28. Morisky DE, Green LW, Levine DM. Concurrent and predictive validity of a self-reported measure of medication adherence. Med Care. 1986:24:67-74.

29. Xu W, Wang W, Liang W. Reliability and validity of Morisky questionnaire in measurement of the adherence to hypertensive medications. Chin J Prev Control Chronic Dis. 2007;15:424-5

30. American Geriatrics Society Beers Criteria Update Expert P. American Geriatrics Society updated beers criteria for potentially inappropriate medication use in older adults. J Am Geriatr Soc. 2012;60:616-31.

31. Yan XL. New revised edition: beers criteria. Chin J Geriatr. 2012;7

32. Wu Y. China report of the development on aging cause. Beijing: Social Sciences Academic Press; 2013 
33. Li L, Guo Y, Chen Z, Chen J, Peto R. Epidemiology and the control of disease in China, with emphasis on the Chinese biobank study. Public Health. 2012;126:210-3.

34. Wang R, Yan Z, Liang Y, Tan EC, Cai C, et al. Prevalence and patterns of chronic disease pairs and multimorbidity among older Chinese adults living in a rural area. PLoS One. 2015;10:e0138521.

35. Barat I, Andreasen F, Damsgaard EM. Drug therapy in the elderly: what doctors believe and patients actually do. Br J Clin Pharmacol. 2001;51:615-22.

36. Blenkiron $\mathrm{P}$. The elderly and their medication: understanding and compliance in a family practice. Postgrad Med J. 1996;72:671-6.

37. Modig S, Kristensson J, Ekwall AK, Hallberg IR, Midlov P. Frail elderly patients in primary care-their medication knowledge and beliefs about prescribed medicines. Eur J Clin Pharmacol. 2009;65:151-5.

38. O'Connell MB, Johnson JF. Evaluation of medication knowledge in elderly patients. Ann Pharmacother. 1992;26:919-21.

39. Okuno J, Yanagi H, Tomura S, Oka M, Hara S, et al. Compliance and medication knowledge among elderly Japanese home-care recipients. Eur J Clin Pharmacol. 1999;55:145-9.

40. Marek KD, Antle L. Medication Management of the Community-Dwelling Older Adult. In: Hughes RG, editor. Patient Safety and Quality: An EvidenceBased Handbook for Nurses. Rockville: Agency for Healthcare Research and Quality (US); 2008.

41. Jin J, Sklar GE, Min Sen OV, Chuen Li S. Factors affecting therapeutic compliance: a review from the patient's perspective. Ther Clin Risk Manag. 2008:4:269-86

42. Costa E, Giardini A, Savin M, Menditto E, Lehane E, et al. Interventional tools to improve medication adherence: review of literature. Patient Prefer Adherence. 2015;9:1303-14.

43. Burge S, White D, Bajorek E, Bazaldua O, Trevino J, et al. Correlates of medication knowledge and adherence: findings from the residency research network of South Texas. Fam Med. 2005;37:712-8.

44. Tsai KT, Chen JH, Wen CJ, Kuo HK, Lu IS, et al. Medication adherence among geriatric outpatients prescribed multiple medications. Am J Geriatr Pharmacother. 2012:10:61-8.

45. Lam P, Elliott RA, George J. Impact of a self-administration of medications programme on elderly inpatients' competence to manage medications: a pilot study. J Clin Pharm Ther. 2011;36:80-6.

46. Sergi G, De Rui M, Sarti S, Manzato E. Polypharmacy in the elderly: can comprehensive geriatric assessment reduce inappropriate medication use? Drugs Aging. 2011:28:509-18

47. Shah BM, Hajjar ER. Polypharmacy, adverse drug reactions, and geriatric syndromes. Clin Geriatr Med. 2012;28:173-86.

48. Marcum ZA, Zheng Y, Perera S, Strotmeyer E, Newman AB, et al. Prevalence and correlates of self-reported medication non-adherence among older adults with coronary heart disease, diabetes mellitus, and/or hypertension. Res Social Adm Pharm. 2013;9:817-27.

49. Pasina L, Brucato AL, Falcone C, Cucchi E, Bresciani A, et al. Medication nonadherence among elderly patients newly discharged and receiving polypharmacy. Drugs Aging. 2014;31:283-9.

50. Turner BJ, Hollenbeak C, Weiner MG, Ten Have T, Roberts C. Barriers to adherence and hypertension control in a racially diverse representative sample of elderly primary care patients. Pharmacoepidemiol Drug Saf. 2009:18:672-81.

51. Guthrie B, Makubate B, Hernandez-Santiago V, Dreischulte T. The rising tide of polypharmacy and drug-drug interactions: population database analysis 1995-2010. BMC Med. 2015;13:74

52. Venturini CD, Engroff $P$, Ely LS, Zago LF, Schroeter G, et al. Gender differences, polypharmacy, and potential pharmacological interactions in the elderly. Clinics (Sao Paulo). 2011:66:1867-72.

53. Chan $K$, Zhang H, Lin ZX. An overview on adverse drug reactions to traditional Chinese medicines. Br J Clin Pharmacol. 2015:80:834-43.

54. Ahmed B, Nanji K, Mujeeb R, Patel MJ. Effects of polypharmacy on adverse drug reactions among geriatric outpatients at a tertiary care hospital in Karachi: a prospective cohort study. PLoS One. 2014;9:e112133.

55. Routledge PA, O'Mahony MS, Woodhouse KW. Adverse drug reactions in elderly patients. Br J Clin Pharmacol. 2004;57:121-6.

56. Al Odhayani A, Tourkmani A, Alshehri M, Alqahtani H, Mishriky A. Potentially inappropriate medications prescribed for elderly patients through family physicians. Saudi J Biol Sci. 2017;24:200-7.
57. Chang CB, Chen JH, Wen CJ, Kuo HK, Lu IS, et al. Potentially inappropriate medications in geriatric outpatients with polypharmacy: application of six sets of published explicit criteria. Br J Clin Pharmacol. 2011;72:482-9.

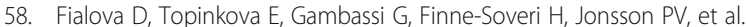
Potentially inappropriate medication use among elderly home care patients in Europe. JAMA. 2005;293:1348-58.

59. Hanlon JT, Schmader KE, Ruby CM, Weinberger M. Suboptimal prescribing in older inpatients and outpatients. J Am Geriatr Soc. 2001;49:200-9.

60. Li H, Pu S, Liu Q, Huang X, Kuang J, et al. Potentially inappropriate medications in Chinese older adults: the beers criteria compared with the screening tool of older persons' prescriptions criteria. Geriatr Gerontol Int. 2017;

61. Zhang X, Zhou S, Pan K, Li X, Zhao X, et al. Potentially inappropriate medications in hospitalized older patients: a cross-sectional study using the beers 2015 criteria versus the 2012 criteria. Clin Interv Aging. 2017;12:1697-703.

\section{Submit your next manuscript to BioMed Central and we will help you at every step:}

- We accept pre-submission inquiries

- Our selector tool helps you to find the most relevant journal

- We provide round the clock customer support

- Convenient online submission

- Thorough peer review

- Inclusion in PubMed and all major indexing services

- Maximum visibility for your research

Submit your manuscript at www.biomedcentral.com/submit 